\title{
Results of Surgical Treatment of Lung Cancer in Patients of Different Age Groups
}

\author{
Alexei L. Charyshkin, $\mathrm{PhD}, \mathrm{ScD}^{1 *}$; Evgeniy A. Toneev ${ }^{2}$ \\ IInstitute of Medicine, Ecology and Physical Education of Ulyanovsk State University \\ ${ }^{2}$ Ulyanovsk Regional Oncology Center \\ Ulyanovsk, The Russian Federation
}

\begin{abstract}
Background: Lung cancer is one of the most common cancers in the world. The main objective of our study was to analyze the results of the surgical treatment of non-small cell lung cancer (NSCLC) in patients of different age groups.

Methods and Results: We examined 280 patients (262/93.6\% men and 18/6.4\% women) aged from 39 to 75 years with NSCLC who underwent surgical treatment in the Ulyanovsk Regional Oncology Center in the period from 2010 to 2016. The mean age of patients was $64.9 \pm 10.1$ years. Concomitant diseases were identified in 256(91.4\%) patients: cardiovascular diseases in 170(60.7\%), chronic obstructive pulmonary disease in $147(52.5 \%)$, lower extremity peripheral artery disease (stages II and III chronic ischemia) in 49(17.5\%), a combination of concomitant pathology in 110(39.3\%) patients. A total of 85(30.4\%) pneumonectomies were performed, 56 of them in patients of young and middle age. Among early postoperative complications, the most frequent complications were purulent-inflammatory complications of the soft tissues of wounds (38.5\%) and bronchopleural fistula (31.1\%). The most severe complications, such as myocardial infarction, acute stroke, and acute limb ischemia, developed in patients with concomitant cardiovascular diseases, which caused the postoperative mortality of $4.6 \%$. There were no statistically significant differences in the structure of postoperative complications depending on sex and age. (International Journal of Biomedicine. 2017;7(2):144-146.)
\end{abstract}

Key Words: non-small cell lung cancer • pneumonectomy • postoperative complications • concomitant diseases

\begin{abstract}
Abbreviations
COPD, chronic obstructive pulmonary disease; LC, lung cancer; MI, myocardial infarction NSCLC, non-small cell lung cancer; PAD, peripheral artery disease.
\end{abstract}

\section{Introduction}

Lung cancer (LC) is the second most common cancer and the leading cause of cancer death in both men and women. ${ }^{(1-7)}$ About 1 out of 4 cancer deaths are from LC. Each year, more people die of lung cancer than of colon, breast, and prostate cancers combined. ${ }^{(8)}$ The number of LC patients

*Corresponding author: Prof. Alexei L. Charyshkin, PhD, $S c D$, Head of the Faculty Surgery Department, Institute of Medicine, Ecology and Physical Education, Ulyanovsk State University. Ulyanovsk, The Russian Federation.E-mail: charyshkin@yandex.ru increases with age, about 2 out of 3 people diagnosed with LC are 65 or older. ${ }^{(6-8,10,11)}$ The risk of oncological pathology and the development of atherosclerotic occlusions of the main vessels sharply increase after age 50 . In elderly patients, the presence of severe concomitant diseases limits radical surgical treatment. Postoperative mortality in LC patients older than 60 years is higher than in young and middle-aged patients. ${ }_{(1,2,12-14)}$ According to the literature, cardiovascular diseases and malignant neoplasms are the most serious problem, as a main cause of premature death, for the developed countries. (4,7,12-14) $^{(1,1)}$ The choice of the optimal treatment option for LC patients with concomitant cardiovascular diseases is still one of the 
most complex and controversial problems. ${ }^{(1,2,9,12-14)}$ The main objective of our study was to analyze the results of the surgical treatment of NSCLC in patients of different age groups.

\section{Materials and Methods}

The study was retrospective, controlled, and nonrandomized. The study was performed in the period from 2010 to 2016. The number of patients for primary selection was 310 ; the number of patients included in the subsequent analysis was 280 .

Inclusion criteria were age 39 years and older, male and female, stage I-III NSCLC, surgery (pneumonectomy or lob-, bilobectomy), and systematic bilateral mediastinal lymphodissection. Exclusion criteria were myocardial infarction and acute cerebrovascular accident.

We examined 280 patients $(262 / 93.6 \%$ men and $18 / 6.4 \%$ women) aged from 39 to 75 years with NSCLC who underwent surgical treatment in the Ulyanovsk Regional Oncology Center in the period from 2010 to 2016.

All patients underwent general clinical and laboratory, radiographic, endoscopic, ultrasound, histological methods of investigation and transthoracic echocardiography. In the preoperative period, primary LC and the presence of metastatic lesions were evaluated using chest radiography in two projections (direct and lateral), the double-contrast barium esophagram, CT of the chest, sputum cytology, bronchological examination, percutaneous transthoracic needle biopsy of peripheral lung lesions, and ultrasound examination of the organs of the abdominal cavity, retroperitoneal space and supraclavicular zones. All patients underwent surgical treatment: pneumonectomy or lob-, bilobectomy, systematic bilateral mediastinal lymphodissection.

The study was conducted in accordance with ethical principles of the Declaration of Helsinki and approved by the by Ethics Committee at the Ulyanovsk Regional Oncology Center. Written informed consent was obtained from all participants.

Statistical analysis was performed using the statistical software «Statistica» (v6.0, StatSoft, USA).

\section{Results and Discussion}

The mean age of patients was $64.9 \pm 10.1$ years and $28.5 \%$ of patients $(\mathrm{n}=80)$ were older than age 60 . Patients older than age 70 accounted for $2.1 \%$ (Table 1 ).

\section{Таблица 1.}

Distribution of patients depending on sex and age

\begin{tabular}{|c|c|c|c|}
\hline \multirow{2}{*}{ Age, $\mathrm{y}$} & \multicolumn{3}{|c|}{ Number of patients } \\
\cline { 2 - 4 } & Men & Women & Total \\
\hline$<45$ & 21 & 3 & $24(8.6 \%)$ \\
\hline $46-60$ & 166 & 10 & $176(62.9 \%)$ \\
\hline $61-70$ & 69 & 5 & $74(26.4 \%)$ \\
\hline$\geq 71$ & 6 & 0 & $6(2.1 \%)$ \\
\hline Total & $262(93.6 \%)$ & $18(6.4 \%)$ & $280(100 \%)$ \\
\hline
\end{tabular}

Stage I NSCLC was detected in $45(16.1 \%)$ patients, stage II NSCLC in 104(37.1\%) patients, and stage IIIA in $131(46.8 \%)$ patients. Central and peripheral LC was determined in $63.9 \%$ and $36.1 \%$ of patients, respectively. Concomitant diseases were identified in 256(91.4\%) patients: cardiovascular diseases in $170(60.7 \%)$, COPD in 147(52.5\%), lower extremity PAD (stages II and III chronic ischemia according to the Fontaine classification modified by Pokrovsky) in $49(17.5 \%$ ), a combination of concomitant pathology in $110(39.3 \%)$ patients. Concomitant pathology was identified in all patients older than age 60 and in 176(88\%) patients under age 60 .

A total of 85(30.4\%) pneumonectomies were performed, 56 of them in patients of young and middle age; a greater number of pneumonectomies $(65.9 \%)$ in this age group was associated with the detection of stage III NSCLC. In elderly and senile age patients, lob- and bilobectomy was performed in 51(63.8\%) patients; at this age, the disease was more often detected at stages II and I.

The 5-year overall survival was $28.9 \%$ whereas the postoperative mortality was $4.6 \%$. Mortality after pneumonectomy was $5.9 \%$ ( 5 of 85 ), after lob-and bilobectomy $-4.1 \%$ (98 of 195).

The postoperative period with complications was detected in 122(43.6\%); the combined complications were observed in $36(12.9 \%)$ patients. There were no statistically significant differences in the structure of complications depending on sex and age. Among early postoperative complications, we identified bronchopleural fistula (31.1\%), hemorrhagic complications (hemothorax, intrapleural hemorrhage) $(11.5 \%)$, purulent-inflammatory complications of the soft tissues of wounds (38.5\%), pleural empyema $(5.7 \%)$, pneumonia $(3.3 \%)$, myocardial infarction $(2.5 \%)$, acute stroke (3.3\%), acute limb ischemia (4.1\%).

The obtained results indicated that the most frequent complications were purulent-inflammatory complications of the soft tissues of wounds (38.5\%) and bronchopleural fistula $(31.1 \%)$. The most severe complications, such as myocardial infarction, acute stroke, and acute limb ischemia, developed in patients with concomitant cardiovascular diseases, which caused the postoperative mortality of $4.6 \%$.

To reduce the number of these complications, it is necessary to improve the preoperative diagnosis and preparation, surgical intervention techniques, and postoperative care. Thus, radical surgical treatment according to indications can be applied to young, middle-age, and older patients with operable NSCLC and allows achievement of satisfactory longterm results and of satisfactory short- and long-term functional results. At the same time, the high number of postoperative complications, in our opinion, is due to the imperfection of preoperative preparation in NSCLC patients with concomitant diseases. In this regard, improving the preoperative diagnosis and preparation in NSCLC patients has important value.

\section{Competing Interests} interests.
The authors declare that they have no competing 


\section{Sources of Funding}

This study was funded by the Ministry of Education and Science of the Russian Federation (the science project No. 18.7236.2017/BCh).

\section{References}

1. Kotiv BN, Habulava GG, Dzidzava II, Nohrin AV, Popov VA, Kuznetsov IM, et al. [Surgical treatment of patients with lung cancer concurrent with coronary artery disease]. Bestnik Rossiiskoi Voenno-Medizinskoi Akademii. 2016;54(2):15-9. [Article in Russian].

2. Kotiv BN, Dzidzava II, Popov VA, Kuznetsov IM. [Surgical treatment of lung cancer in patients with low functional reserves of respiratory system and blood circulation]. Bestnik Rossiiskoi Voenno-Medizinskoi Akademii. 2016;54(2):241-6. [Article in Russian].

3. Key Statistics for Lung Cancer [Internet]: The American Cancer Society Available from https://www.cancer.org/cancer/ non-small-cell-lung-cancer/about/key-statistics.html

4. Charyshkin AL, Yudin AN. [Anesthesia and prevention of inflammatory complications at patients after median sternotomy]. The Russian Journal of Thoracic and Cardiovascular Surgery. 2014;(6):28-33. [Article in Russian]. 5. Chernykh AV. [Contemporary variants of treatment of nonsmall cell lung carcinoma]. Vestnik of St. Petersburg State University (Series 11 "Medicine"). 2009;(2):150-63. [Article in Russian].

6. Chernykh A.V. [Systematic mediastinal bilateral lymph dissection in lung carcinoma treatment: surgical approach perfection]. I.P. Pavlov Russian Medical Biological Herald. 2009;(2):121-6. [Article in Russian].

7. Al-Attar N, Salvi S, Sebbag U, Nataf P. Combined left pneumonectomy and off-pump coronary artery bypass through left thoracotomy. Eur J Cardiothorac Surg. 2001;19(2):226-8. 8. Ambrogi V, Pompeo E, Elia S, Pistolese GR, Mineo TC. The impact of cardiovascular comorbidity on the outcome of surgery for stage I and II non-small-cell lung cancer. Eur J Cardiothorac Surg. 2003;23(5):811-7.

9. Basavaraju SR, Jones TD. Atherosclerotic risks from chemicals: part I. Toxicological observations and mechanisms of atherosclerosis. Arch Environ Contam Toxicol. 1998;35(1):152-64.

10. Charyshkin AL, Yudin AN. The results of treatment of patients after median sternotomy. Life Science Journal. 2014;11(11):342-5.

11. Danton MH, Anikin VA, McManus KG, McGuigan JA, Campalani G. Simultaneous cardiac surgery with pulmonary resection: presentation of series and review of literature. Eur J Cardiothorac Surg. 1998;13(6):667-72.

12. Dyszkiewicz W, Jemielity M, Piwkowski C, Kasprzyk M, Perek B, Gasiorowski L, et al. The early and late results of combined off-pump coronary artery bypass grafting and pulmonary resection in patients with concomitant lung cancer and unstable coronary heart disease. Eur J Cardiothorac Surg. 2008;34(3):531-5. doi: 10.1016/j.ejcts.2008.05.017.

13. Hercberg S, Galan P, Preziosi P, Alfarez MJ, Vazquez C. The potential role of antioxidant vitamins in preventing cardiovascular diseases and cancers. Nutrition. 1998;14(6):513-20.

14. Hirose H, Amano A, Yoshida S, Nagao T, Sunami H, Takahashi A, et al. Coronary artery bypass grafting in patient with malignant neoplasm. Efficacy of coronary artery bypass grafting on beating heart. Jpn J Thorac Cardiovasc Surg. 2000;48(2)96-100.

15. Johnson JA, Landreneau RJ, Boley TM, Haggerty SP, Hattler $\mathrm{B}$, Curtis JJ, et al. Should pulmonary lesions be resected at the time of open heart surgery? Am Surg. 1996;62(4)300-3. 